Supporting information

\title{
Metal Reclamation from Spent Lithium-ion Battery Cathode Materials: Directional Conversion of Metals Based on Hydrogen Reduction
}

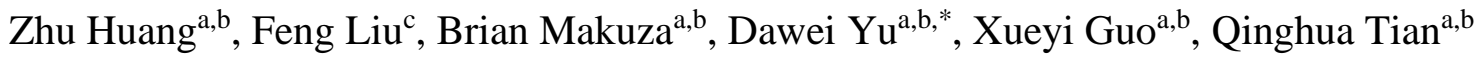 \\ ${ }^{a}$ School of Metallurgy and Environment, Central South University, 932 Lushan South Road, \\ Changsha, Hunan 410083, China \\ ${ }^{b}$ National and Regional Joint Engineering Research Center of Nonferrous Metal Resource \\ Recycling, 932 Lushan South Road, Changsha, Hunan 410083, China \\ ${ }^{c}$ Department of Materials Science and Engineering, University of Toronto, 184 College Street, \\ Toronto, Ontario M5S3E4, Canada \\ *Corresponding author: Dawei Yu \\ Email: dawei.yu@csu.edu.cn \\ Tel: $(+86) 0731-88876255$
}

\section{Content of Supporting information}

Number of pages: $\quad 5$

Number of Figures: $\quad 6$

Number of Tables: $\quad 2$ 


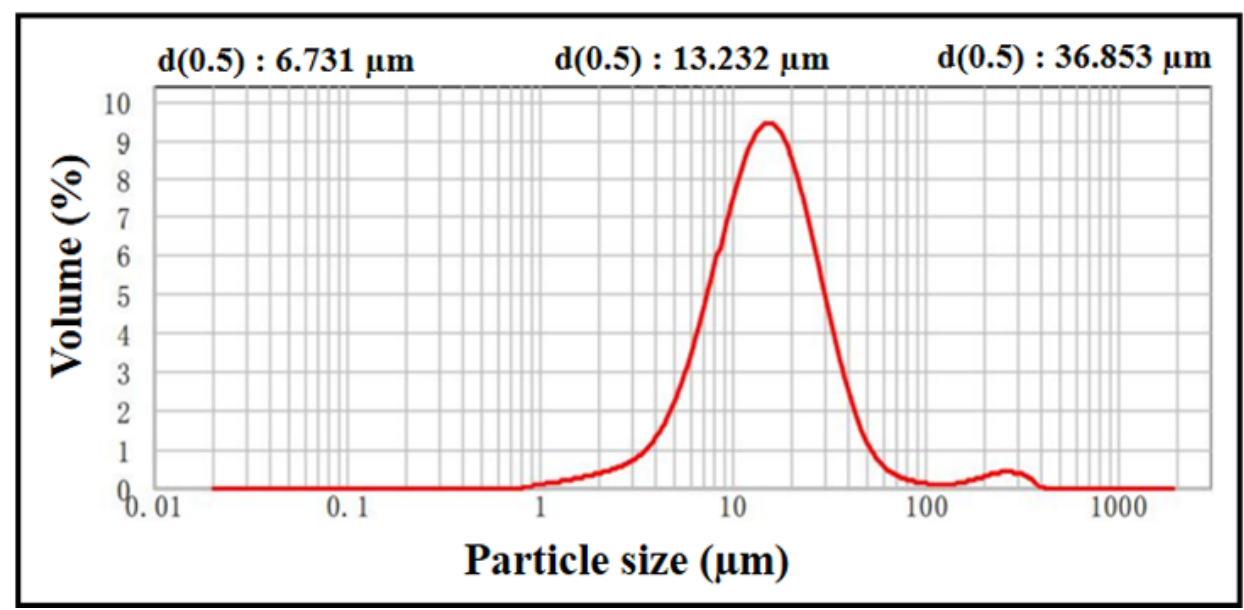

Figure S1. Particle size analysis of the untreated cathode powders of the Li-ion batteries used in the study.

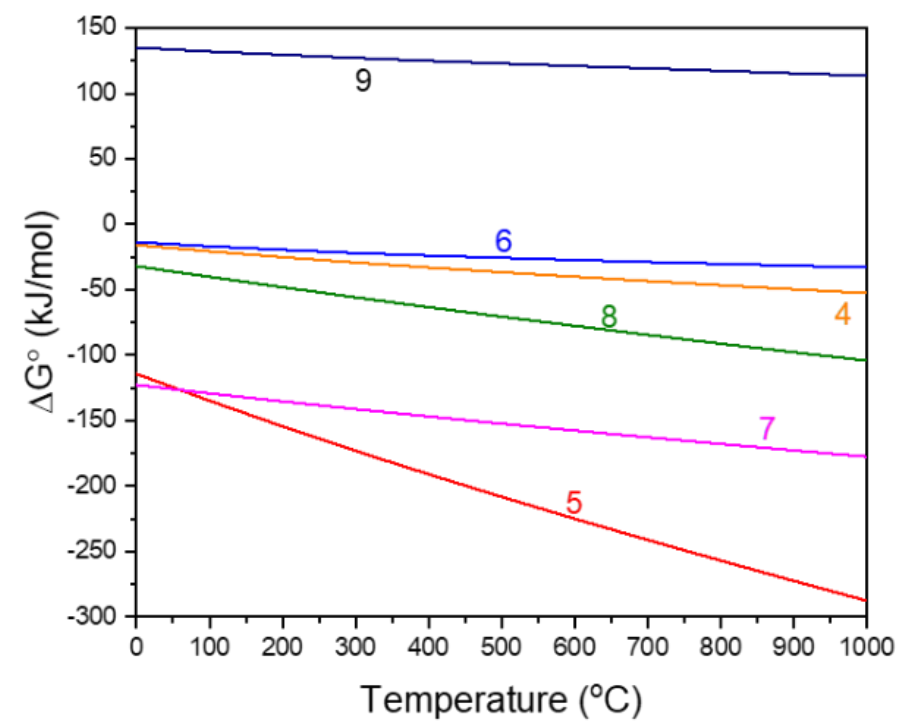

Figure S2. The relationship between $\Delta \mathrm{G}^{0}(\mathrm{~kJ} / \mathrm{mol})$ and temperature $\left({ }^{\circ} \mathrm{C}\right)$ for hydrogen reduction of the relevant metal oxides (The numbering in this figure corresponds to eqs 4-9 in the paper). 


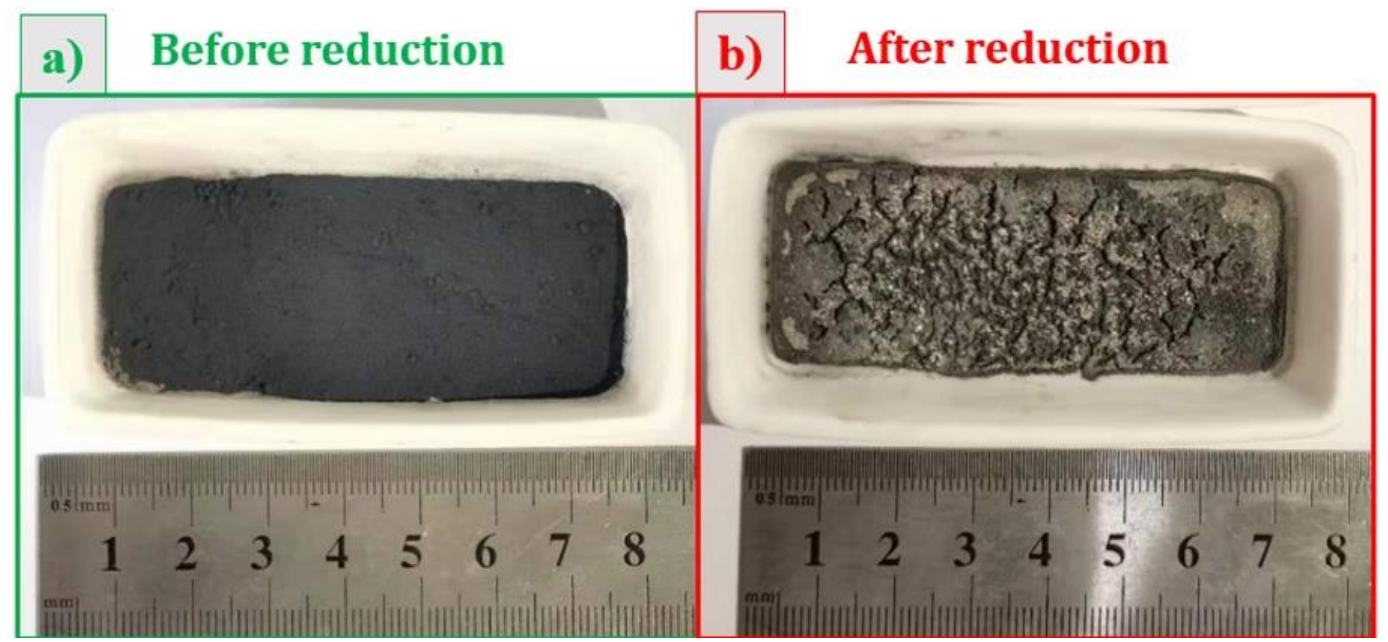

Figure S3. Comparison of the cathode material: (a) before reduction, (b) after hydrogen reduction at $1000{ }^{\circ} \mathrm{C}$ for 90 minutes.

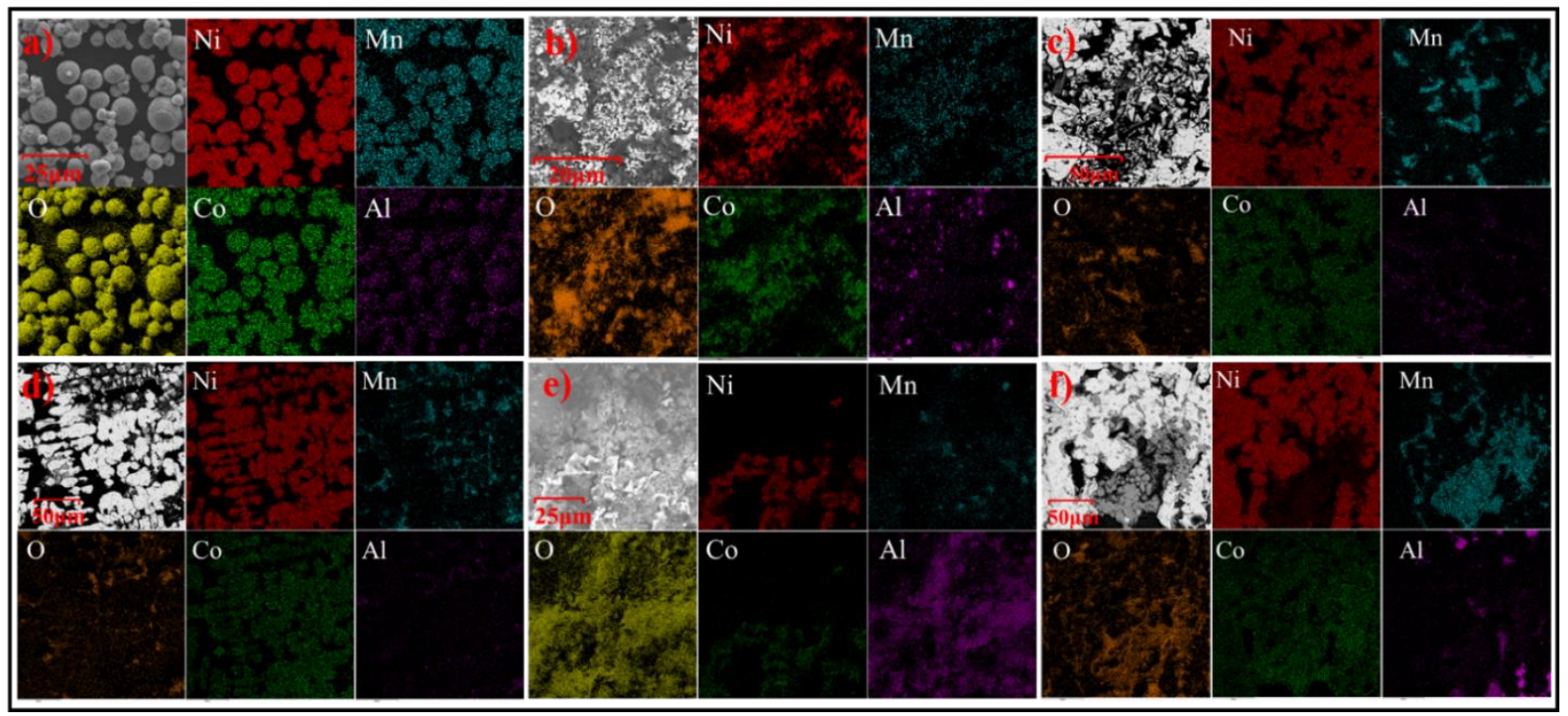

Figure S4. The SEM and elemental mapping images of the reduction products obtained under different reduction temperatures: a) starting materials; b) $600{ }^{\circ} \mathrm{C}$; c) $700{ }^{\circ} \mathrm{C}$; d) $800{ }^{\circ} \mathrm{C}$; e) $900{ }^{\circ} \mathrm{C}$; f) $1000{ }^{\circ} \mathrm{C}$. 


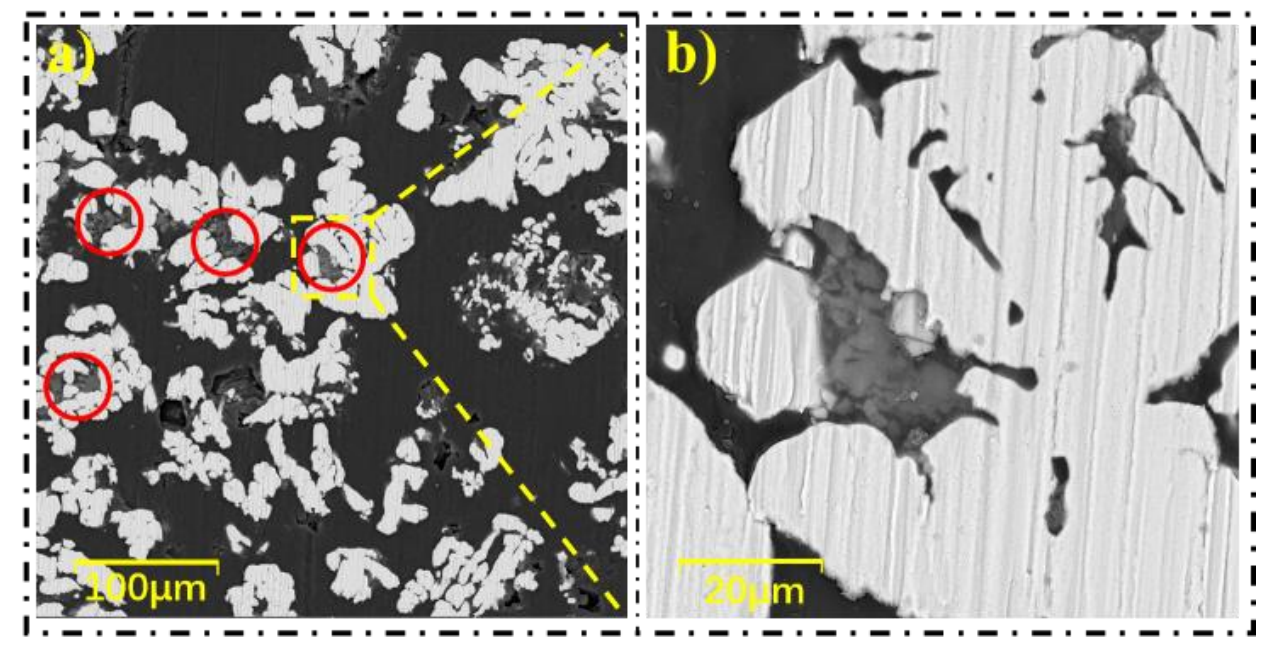

Figure S5. SEM micrographs of the magnetic fraction recovered after wet magnetic separation showing the $\mathrm{MnO}$ particles (marked by red circles) wrapped in magnetic alloy particles (reduction temperature 800 ${ }^{\circ} \mathrm{C}$, reduction time $\left.90 \mathrm{~min}\right)$.
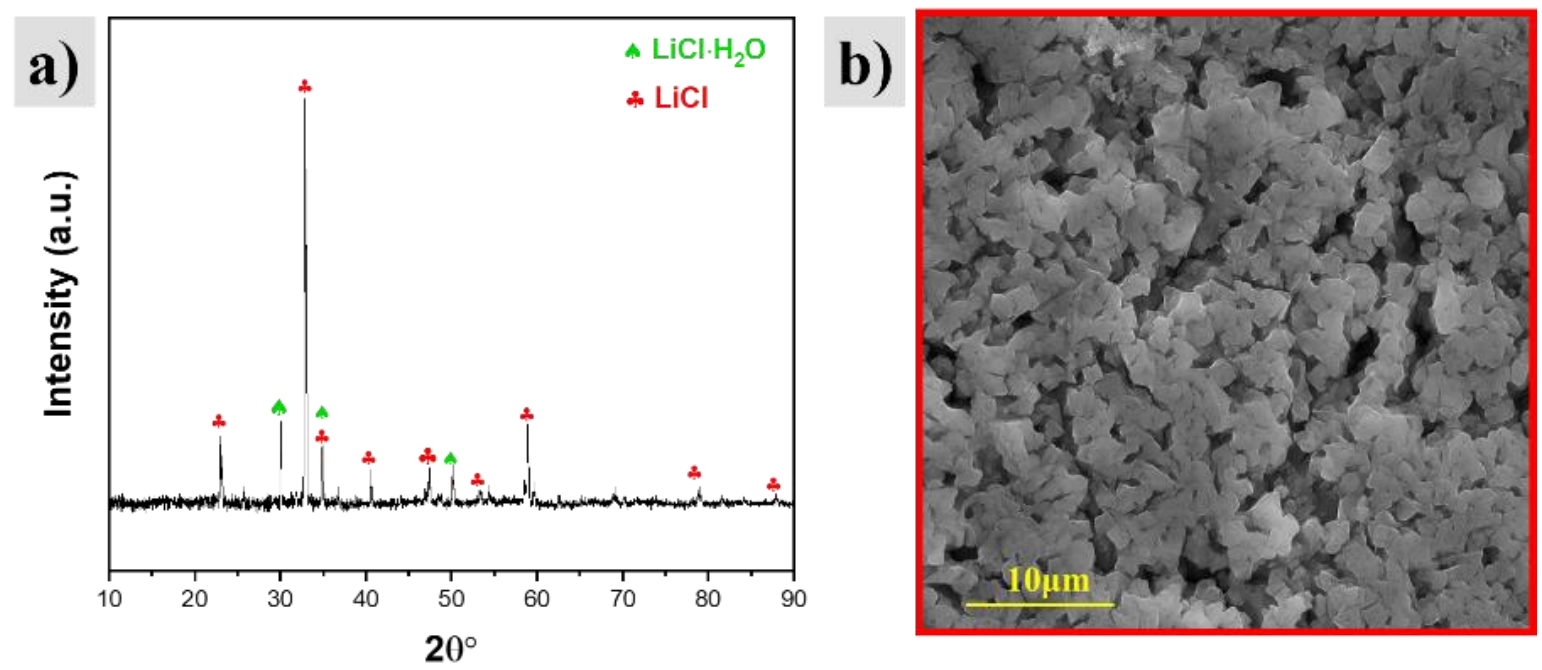

Figure S6.XRD diffractogram and b) SEM micrograph of the recovered lithium chloride after purification of the water leaching solution, which was obtained from the following experimental conditions: reduction temperature $800^{\circ} \mathrm{C}$, reduction time $90 \mathrm{~min}$, grinding time $1 \mathrm{~min}$, liquid: solid ratio $50 \mathrm{~mL} / \mathrm{g}$ for water leaching. 
Table S1. ICP chemical analysis of the water leaching solution (mg/L)

\begin{tabular}{cccccc}
\hline Element & $\mathrm{Li}$ & $\mathrm{Al}$ & $\mathrm{Mn}$ & $\mathrm{Ni}$ & $\mathrm{Co}$ \\
\hline Composition & 421.4 & 26.9 & 0.0068 & 0.002 & 0.0001 \\
\hline
\end{tabular}

Table S2. ICP chemical analysis of the obtained $\mathrm{LiCl}$ product (wt\%)

\begin{tabular}{cccccc}
\hline Element & $\mathrm{Li}$ & $\mathrm{Al}$ & $\mathrm{Mn}$ & $\mathrm{Ni}$ & $\mathrm{Co}$ \\
\hline Composition & 15.21 & 0.0143 & 0.0008 & 0.0012 & 0.0001 \\
\hline
\end{tabular}

